\title{
Assessing Consumer Preferences of Scab-resistant Apples: A Sensory Evaluation
}

\author{
Kathleen Kelley ${ }^{1,4,6}$, Jeffrey Hyde ${ }^{2,4}$, James Travis ${ }^{3,5}$, and \\ Robert Crassweller ${ }^{1,5}$
}

ADDITIONAL INDEX wORDs. attitudes, behaviors, marketing, demographic, local, organic, segmentation, Malus $\times$ domestica

Summary. One hundred forty-nine consumers participated in a sensory evaluation, conducted on 14 Nov. 2008, at The Pennsylvania State University, University Park, PA, to determine consumer acceptance and perceptions of scab-resistant apples (Malus $\times$ domestica). Consumers were exclusively screened for liking and eating apples. The study provides tree fruit growers and marketers in the mid-Atlantic United States with information on consumer preferences for apples that might substitute for common cultivars that require frequent apple scab pesticide applications. Resistant cultivars are also attractive in organic production systems. During the 10-minute sensory evaluation, panelists rated five scab-resistant apples ['Crimson Crisp', 'GoldRush', NY 75907-49 (NY 49), 'Crimson Topaz', and 'Sundance'] and a commercially available non-resistant cultivar, Jonagold, on appearance, aroma, texture, flavor, and overall liking using a nine-point hedonic scale ( 9 = "like extremely" and 1 = "dislike extremely"). Three of the four apples tested with a red peel ('Crimson Topaz', NY 49, and 'Crimson Crisp') were rated significantly higher than the other apples on the basis of appearance, receiving mean ratings that were between "like moderately" and "like very much," a rating of 7 and 8, respectively. In regards to texture, 'Crimson Topaz' and 'Crimson Crisp' were significantly higher than 'Jonagold' and NY 49, with mean ratings between "like slightly" and "like moderately." For overall liking scores, 'Crimson Crisp', which was rated between "like slightly" and "like moderately," was not significantly different from 'Crimson Topaz' and 'GoldRush'; however, 'Crimson Crisp' was rated higher than 'Jonagold', NY 49, and 'Sundance'. Panelists also responded to questions regarding their food-purchasing attitudes and behaviors. Sixty-two percent of panelists purchased fresh apples for themselves and/or other household members at least "two or three times a month" during an average year. Only $2.7 \%$ responded that they purchased fresh apples "more than once a week." This study of consumer preferences provides an initial assessment of the feasibility of marketing new apple cultivars and organic apples within the mid-Atlantic U.S. region. Those that performed well in the sensory evaluation should be candidates for additional market research.

A $s$ growers consider strategies to differentiate their businesses and identify a competitive advantage, such as producing

\footnotetext{
Use of trade names does not imply endorsement of the products named or criticism of similar ones not named.

The authors thank the Nesbitt Faculty Program Development Award for funding this research.

The authors also thank Julie Peterson and Ellen Mahan, Sensory Evaluation Laboratory, Department of Food Science, Pennsylvania State University for their assistance with the sensory evaluation.

${ }^{1}$ Department of Horticulture, The Pennsylvania State University, University Park, PA 16802

${ }^{2}$ Department of Agricultural Economics and Rural Sociology, The Pennsylvania State University, University Park, PA 16802

${ }^{3}$ Department of Plant Pathology, The Pennsylvania State University, University Park, PA 16802

${ }^{4}$ Associate Professor

${ }^{5}$ Professor

${ }^{6}$ Corresponding author. E-mail: kmk17@psu.edu.
}

apples labeled certified organic, pesticidefree, or integrated pest management, it is essential to investigate consumer attitudes toward these labels and to determine if apples suitable for these production systems have a pleasing taste, texture, and visual appearance. Consumers are able to accurately detect apple maturity based on visual characteristics (Richardson-Harman et al., 1997), which can be an indication of eating quality. However, this is an imperfect indication because apples with similar appearances may have very different sensory characteristics such as aroma, texture, and flavor. Therefore, it is critical that sensory performances of these characteristics be evaluated for each apple. This information helps growers make production and marketing decisions as breeders develop new cultivars, as lesser-known cultivars from abroad are imported, and as heirloom cultivars are rediscovered.

A substantial amount of research is necessary to determine the feasibility of introducing consumer products into the market place and assess potential consumer demand. Among the tools available for this process, sensory evaluation is used by marketers to investigate consumer preference for new food products, helping to narrow potential market introductions to a manageable number. In addition to being subjected to other selection criteria, many commonly recognized cultivars such as 'Fuji', 'Braeburn', and 'Gala' (McCracken et al., 1994) underwent sensory evaluation before becoming readily available at grocery stores and supermarkets. Retail introduction of a new apple cultivar is risky for producers (because they must plant an orchard that may last for 25 or more years) and retailers (because they must bear costs of advertising and promotion and allocate shelf space that could go to another product). Therefore, it would be ideal to identify cultivars that provide consumers with direct (e.g., flavor, texture, increased shelf life) and/or indirect (e.g., country of origin, locally grown, certified organic, reduced pesticide use) benefits.

As interest in certified-organic products continues to increase in the United States, with further growth expected during the next decade (The NPD Group, 2009), apple cultivars resistant to apple scab (caused by the fungus Venturia inaequalis) are candidates to fulfill demand for organic apples and provide concerned growers with a tool to decrease pesticide use. Identifying scab-resistant apple cultivars (which tend to be less known to the average U.S. consumer) suitable for production in scab-affected regions and for fresh consumption has

\begin{tabular}{llll}
\hline $\begin{array}{l}\text { Units } \\
\begin{array}{l}\text { To convert U.S. to SI, } \\
\text { multiply by }\end{array}\end{array}$ & U.S. unit & SI unit & $\begin{array}{l}\text { To convert SI to U.S., } \\
\text { multiply by }\end{array}$ \\
\hline 29.5735 & $\mathrm{fl} \mathrm{oz}$ & $\mathrm{mL}$ & 0.0338 \\
$\left({ }^{\circ} \mathrm{F}-32\right) \div 1.8$ & ${ }^{\circ} \mathrm{F}$ & ${ }^{\circ} \mathrm{C}$ & $\left(1.8 \times{ }^{\circ} \mathrm{C}\right)+32$
\end{tabular}


been the subject of a select number of research studies. These studies used various methods such as small groups of panelists trained to describe sensory attributes (e.g., crispness, juiciness, perfumed flavor) for several $(n=24)$ cultivars (Kuhn and Thybo, 2001 ) and sensory evaluations involving European or other foreign audiences (Cmelik et al., 2007). Other studies have used conjoint analysis to identify the most important attribute (e.g., taste, skin color, method of production, price) and level of attribute (e.g., sweet/tart, red-skin/ green-skin, conventionally grown/ organically grown) to consumers after reading product descriptions (Baker, 1999; Jerko and Damir, 2008; Manalo, 1990). Research results from such studies have indicated the importance of indicating reduced pesticide use in the product description (Baker, 1999).

Objectives specific to this study include: 1) investigating whether lesserknown scab-resistant fresh apple cultivars suitable for production in the mid-Atlantic U.S. region appeal to consumers who were selected because they indicated that they liked apples and frequently ate apple slices; and 2) better understanding the attitudes, behaviors, and demographics of consumers who desire locally grown and certified-organic apples.

\section{Materials and methods}

Apples Tested. A sensory evaluation was conducted on 14 Nov. 2008 at the Sensory Evaluation Laboratory at The Pennsylvania State University, University Park, PA, to determine which lesser-known scab-resistant fresh apples consumers preferred on the basis of appearance, aroma, texture, flavor, and overall appeal. Apples 'Crimson Topaz' (Brown and Maloney, 2008), 'Jonagold' (Greene et al., 1997), NY 75907-49 (NY 49; S. Brown, personal communication), 'Sundance' (Janick et al., 2004), 'GoldRush' (Crosby et al., 1994), and 'Crimson Crisp' (Janick et al., 2006) were chosen on the basis of previous sensory evaluations as showing promise for fresh market use (Miller et al., 2005, 2007). However, they are not prevalent on retail shelves. Hence, the need to determine consumer acceptability is warranted.

Five of the six apples were grown at the Horticulture Research Farm,
Rock Spring, PA, according to the Pennsylvania Tree Fruit Production Guide (Crassweller, 2008) and were delivered to the laboratory $4 \mathrm{~d}$ before testing and stored in a $35^{\circ} \mathrm{F}$ walkin cooler. 'GoldRush' apples were grown at the Fruit Research and Extension Center, Biglerville, PA, because they are a late-maturing cultivar that benefit from a brief period of storage, and were delivered the morning of the test. Additional selection criteria for apples were based on their resistance to apple scab either described in the released papers or determined by the breeder and suitability for eating fresh.

The test was limited to six apples to prevent sensory fatigue (Meilgaard et al., 2008). The cultivar 'Jonagold', which is scab susceptible, was selected to serve as a control since it is commercially available and has been used as a reference sample in other evaluations (Cmelik et al., 2007). A description of the sensory profile for apples tested is presented in Table 1 . The protocol and survey instrument were approved by the Office for Research Protections and Biomedical Institutional Review Board at The Pennsylvania State University. All fruit were harvested on the basis of the Generic Cornell Starch Iodine Chart rating of 4 to 6 , which is considered optimum maturity for fresh consumption (Miller et al., 2005).

SENSORY EVALUATION PROCEDURE. Participants were recruited from the university and local community through e-mail invitations sent to listserve members, individuals who were recruited by staff at the Sensory Evaluation Laboratory or who asked to be added to the directory. All participants were pre-screened to select consumers who like apples and eat sliced apples (Hampson et al., 2000). If their answer to the screener criterion was positive, they were asked to participate. A quantitative affective testing approach, conducted with an untrained panel, was implemented to determine the target audience's level of acceptability and preference (Meilgaard et al., 2008) for apples tested.

During the sensory evaluation, apples were cored and cut into 10 slices of similar size, and three slices of each sample were served in clear plastic cups labeled with three-digit blinding codes. To minimize unwanted browning, apples were cut just before being served and placed on each serving tray in a randomized order, along with a $5-\mathrm{fl} \mathrm{oz}$ glass of water (for panelists to use to cleanse their palate) and a napkin. Blind samples were served to reduce any possible bias (Resurreccion, 1998) participants might have for a particular apple. A nine-point hedonic scale $(9=$ "like extremely," $5=$ "neither like nor dislike," l = "dislike extremely") was used to evaluate appearance, aroma, texture, flavor, and overall appeal (Meilgaard et al., 2008) of lesser-known scab-resistant fresh apples. This scale was chosen to measure likeability since it is easy to understand with minimal instruction (Stone and Sidel, 2004). Evaluations took place in individual testing booths, using Compusense $^{\circledR}$ five software (Compusense $^{\circledR}$, Guelph, ON, Canada), a sensory and consumer research data collection program.

Each participant signed a consent form that they met the screener criteria and acknowledged that they would receive an incentive to participate. They were then instructed to sit at a computer-equipped booth and to begin the sensory evaluation by using either the mouse or the keyboard to select their responses from the computer screen. Panelists were first asked to evaluate the appearance of whole apple versions of samples, presented as images on their computer screen, before evaluating the sample slices. Images for each apple were presented instead of real apples to preserve visual quality throughout the evaluation and to reduce visual variability between apples. According to results from a study where digital images were used to determine consumer preferences for visual characteristics of apples, digital imagery "is a powerful tool for controlling variation in visual samples" (Cliff et al., 2002). Each image included a side view, stem-end view, and blossom-end view. Panelists were then instructed to evaluate the aroma, texture, flavor, and overall liking for the corresponding apple slices. After all samples were evaluated, panelists were asked to rank them in order from most preferred to least preferred (Resurreccion, 1998).

Panelists were then directed to answer a variety of psychographic and behavioral questions that pertained to the following: 1) the frequency with which they purchase fresh apples for 
Table 1. Description of sensory characteristics for six scab-resistant apples evaluated during a sensory evaluation conducted on 14 Nov. 2008.

\begin{tabular}{|c|c|}
\hline Apples tested & Sensory characteristics and descriptions \\
\hline NY 49 & $\begin{array}{l}\text { Red peel. High sugar-to-acid ratio with a white flesh and good firmness and crisp texture. Parentage: } \\
\text { 'Empire' } \times \text { 'Redfree', from a cross made in } 1979 \text { at the New York State Agricultural Experiment Station. }\end{array}$ \\
\hline 'Jonagold'y & $\begin{array}{l}\text { Bicolor red over yellow peel. Fruit are sweet-tart and very juicy. Parentage: 'Golden Delicious’ × 'Jonathan', } \\
\text { from the New York State Agricultural Experiment Station, introduced in } 1968 .\end{array}$ \\
\hline 'Sundance' & $\begin{array}{l}\text { Whitish to cream flesh color and greenish color peel. Flavor is described as sweet and tart. Parentage: 'Golden } \\
\text { Delicious' } \times \text { PRI } 1050-201 \text { (1050NJ1), from PRI program. }\end{array}$ \\
\hline
\end{tabular}

'Jonagold' was selected to serve as a scab-susceptible control since it is commercially available and has been used as a reference sample in other evaluations (Cmelik et al., 2007).

themselves and/or other household members; 2) the most important factor when purchasing fresh apples to be eaten raw (e.g., apple cultivar or type, apple sweetness/tartness level, price); 3 ) whether they and/or other household members had dietary needs that required a diet consisting mainly of fruits and/or vegetables; 4) their attitudes toward, and purchasing history of, locally grown and certified-organic produce; and 5) their reasons for purchasing produce directly from the farmer or from other sources, which is labeled locally grown. Some questions required a "yes" or "no" response while others asked participants to indicate their agreement or disagreement based on a five-point Likert scale ( $5=$ "strongly agree," l = "strongly disagree"). Participants also indicated the frequency with which they take action, including purchasing products. Demographic questions were used to gather information pertaining to the panelists' gender, age range, ethnicity, affiliation with the university, number of adults and children in the household, 2007 gross household income, education level, and city and state of their permanent residence. Upon completion of the sensory evaluation, participants were given $\$ 10.00$ for their participation (Kelley and Sánchez, 2005).

Liking scores for each sample were analyzed using Tukey's honestly significant difference (HSD) in Compusense ${ }^{\circledR}$ five software. Rank was analyzed using Friedman analysis of rank $(\alpha=0.05)$ followed by Tukey's $\operatorname{HSD}(\alpha=0.05)$ in Compusense ${ }^{\circledR}$ five. Data pertaining to consumer behavior and preference questions were analyzed with SPSS (version 17; SPSS, Chicago, IL) using Pearson's chisquare statistic $(P \leq 0.05)$.

\section{Results and discussion Demographic profile}

Of the 149 participants, the most common responses to demographic questions show that panelists can be characterized as follows: female $(80.5 \%)$; Caucasian $(88.6 \%)$; a member of a two-adult household (47.7\%); with no children at home (56.4\%); age 37 years and older (60.4\%); had either obtained some level of high school education, were high school graduates, or had obtained some level of college/technical school education but had not graduated (58.4\%); were staff members at the university $(67.8 \%)$; with a household income of $\$ 74,999$ or lower $(61.1 \%)$. The number of consumers who participated in the study was deemed acceptable on the basis of research results that indicated a minimum of 112 consumers would be necessary for evaluations where an objective is to determine significant differences between samples (Hough et al., 2006).

Pertaining to issues that may impact the amount of fruits and/or vegetables included in their daily diet, participants were asked to indicate if they and/or another member of their household were vegetarians. Six participants $(4.0 \%)$ responded positively to this question, with four of these individuals indicating that they were between the ages of 18 and 24 years and the other two indicating that they were between the ages of 25 and 48 years. Even though a majority of participants (69.1\%) indicated that no one in the household was a vegetarian, $24.2 \%$ responded that "a majority of the foods [they] eat are fruits and/or vegetables."

\section{Sensory evaluation outcomes}

Appearance. Samples 'Crimson Topaz' (mean rating $=7.74)$, NY 49 (7.60), and 'Crimson Crisp' (7.54) were rated significantly higher on appearance than the other samples, receiving mean liking ratings that fell between "like moderately" (7.0) and "like very much" (8.0) (Table 2). Samples 'Sundance' (6.30) and 'GoldRush' (5.99) were rated significantly lower than the other samples. Higher liking ratings for 'Crimson Topaz', NY 49, and 'Crimson Crisp', all having red peels, compared with 'Sundance' and 'GoldRush', both with yellow peels, may be, according to research, because consumers prefer apples with a red peel (Cliff et al., 2002; Czernyszewicz, 2009; Jesionkowska et al., 2006).

Aroma. Aroma results show that NY 49 apples (6.86) were rated significantly higher for liking than 'Crimson Topaz' (6.40), 'GoldRush' (5.58), 'Jonagold' (6.42), and 'Sundance' (5.62) apples, but not 'Crimson Crisp' apples (6.54); the aroma results for the 'Crimson Crisp' apples were significantly different from those for the 'GoldRush' and 'Sundance' apples. Mean liking ratings of samples NY 49 and 'Crimson Crisp' fell between "like slightly" (6.0) and "like moderately" (7.0), while mean liking ratings for the 'GoldRush' and Sundance apples, which had significantly lower scores than the other samples, 
Table 2. Panelists' rating of appearance, aroma, texture, flavor, and overall liking scores for six apples evaluated during a sensory evaluation conducted on 14 Nov. 2008 involving 149 consumer participants.

\begin{tabular}{|c|c|c|c|c|c|c|}
\hline $\begin{array}{l}\text { Sensory } \\
\text { characteristic } \\
\text { tested }(1-9 \text { scale })^{\mathrm{z}}\end{array}$ & \multicolumn{6}{|c|}{ Apples evaluated } \\
\hline Appearance & $7.54 \mathrm{a}^{\mathrm{x}}$ & $7.74 \mathrm{a}$ & $5.99 \mathrm{c}$ & $7.12 \mathrm{~b}$ & $7.60 \mathrm{a}$ & $6.30 \mathrm{c}$ \\
\hline Texture & $6.99 \mathrm{a}$ & $6.92 \mathrm{a}$ & $6.56 \mathrm{ab}$ & $5.65 \mathrm{c}$ & $6.18 \mathrm{bc}$ & $6.60 \mathrm{ab}$ \\
\hline Flavor & $6.70 \mathrm{a}$ & $6.42 \mathrm{a}$ & $6.19 \mathrm{ab}$ & $6.36 \mathrm{a}$ & $6.20 \mathrm{ab}$ & $5.68 \mathrm{~b}$ \\
\hline Overall & $6.72 \mathrm{a}$ & $6.56 \mathrm{ab}$ & $6.23 \mathrm{abc}$ & $6.09 \mathrm{bc}$ & $6.14 \mathrm{bc}$ & $5.76 \mathrm{c}$ \\
\hline
\end{tabular}

${ }^{\mathrm{z} 9}$ = like extremely, 8 = like very much, 7 = like moderately, 6 = like slightly, $5=$ neither like nor dislike, 4 = dislike slightly, $3=$ dislike moderately, $2=$ dislike very much, and 1 = dislike extremely.

'Jonagold' was selected to serve as a scab-susceptible control since it is commercially available and has been used as a reference sample in other evaluations (Cmelik et al., 2007). ${ }^{\mathrm{x}}$ Means with different letters within rows are significantly different $(P \leq 0.05)$. Significance was determined using analysis of variance, followed by Tukey's HSD in Compusense ${ }^{\circledR}$ five software (Compusense ${ }^{\circledR}$, Guelph, ON, Canada).

fell between "neither like nor dislike" (5.0) and "like slightly" (6.0).

Texture. Samples 'Crimson Topaz', 'GoldRush', 'Sundance', and 'Crimson Crisp' did not differ significantly in texture liking (6.92, $6.56,6.60$, and 6.99 , respectively); these mean scores range between "like slightly" (6.0) and "like moderately" (6.0). 'Crimson Topaz' and 'Crimson Crisp' apples were rated significantly higher than NY 49 (6.18) and 'Jonagold' apples (5.65), which received mean scores between "like slightly" (6.0) and "neither like nor dislike" (5.0). 'Jonagold' apples received texture scores significantly lower than all samples except for NY 49.

Flavor. Liking scores for flavor were not significantly different between the 'Crimson Topaz', 'GoldRush', 'Jonagold', NY 49, and 'Crimson Crisp' apples $(6.42,6.19,6.36$, 6.20 , and 6.70 , respectively). Likewise, scores for 'GoldRush', NY 49, and 'Sundance' (5.68) were not found to be significantly different. 'Crimson Topaz', 'Jonagold', and 'Crimson Crisp' samples received significantly higher flavor liking scores than 'Sundance'. All samples received scores between "like slightly" (6.0) and "like moderately" (7.0) except 'Sundance', which scored between "neither like nor dislike" (5.0) and "like slightly" (6.0).

Overall LIKING. For overall liking scores, 'Crimson Crisp' apples (6.72) received significantly higher scores than 'Jonagold', NY 49, and 'Sundance' apples $(6.09,6.14$, and 5.76 , respectively). 'Sundance' apples, which were rated between "neither like nor dislike" (5.0) and "like slightly" (6.0), received significantly lower overall liking scores than 'Crimson Topaz' apples (6.56) and
'Crimson Crisp' apples, both of which were rated between "like slightly" (6.0) and "like moderately" (7.0). 'Crimson Topaz', 'GoldRush' (6.23), 'Jonagold', and NY 49 samples were not found to be significantly different from one another for overall liking; 'GoldRush', 'Jonagold', and NY 49 apples all received mean ratings just above 6.0 ("like slightly").

\section{Fresh apple-purchasing behavior}

When asked to report the frequency with which they purchase fresh apples for themselves and/or other household members, the majority of participants purchased fresh apples "about once a week" $(30.2 \%)$, followed by "two to three times a month" (28.9\%), "about once a month" $(24.2 \%)$, "a few times a year" (13.4\%), and "more than once a week" $(2.7 \%)$. No differences existed when analyzed by demographic characteristic except when examined by income and for those who purchased fresh apples "a few times a year." Participants stating that they had an annual income between $\$ 50,000$ and $\$ 74,999$ were less likely to purchase at this interval $(2.7 \%)$ than those who reported having an income less than $\$ 25,000$ and those with an income between $\$ 25,000$ and $\$ 49,999,21.1 \%$ and $25.7 \%$, respectively (Table 3 ).

Participants were asked to select, from a list of 17 options, the one characteristic they consider most important when purchasing fresh apples to be eaten raw. Options included apple features (e.g., cultivar/type, sweetness level, visual appeal), packaging options (e.g., multiples in one bag, apples sold individually), production issues (e.g., country of origin, locally grown, certified organic), and promotion (e.g., suggested by others, samples available, in-store signage and advertising). As a whole, participants selected "apple cultivar or type of apple" (33.6\%), "sweetness level" (18.1\%), and "past purchase of a particular apple cultivar" $(15.4 \%)$ as the top three characteristics they consider most important when purchasing fresh apples to be eaten raw.

Data were then analyzed to determine if responses to this question and others were significantly different based on several demographic characteristics. Based on education level, participants who completed some college or had a technical degree were more likely to select "sweetness level" as the most important characteristic $(33.3 \%)$ compared with participants who had a high school diploma or less $(9.8 \%)$ (Table 3). The percent of participants in these two groups who selected "sweetness level" did not differ from those with either a bachelor's degree $(17.6 \%)$ or a master's degree or higher (14.3\%). Of the differences detected, two-adult households were less likely $(7.0 \%)$ to base fresh apple purchases on "past purchase of a particular apple cultivar" than households with three or more adults $(28.3 \%)$. Only one participant stated that "apple is certified organic" was the most important characteristic. Characteristics that were less than $10 \%$ and were not significantly different based on demographic segment were as follows: nutritional value of the apple, quantity of apples available, multiple number of apples in one package, size of apple, sign or other in-store advertising, country where the apple was grown, apple that was certified organic, and suggestion from family member or friend. 


\section{Conclusion}

Though the sample may not be completely representative of consumers in the mid-Atlantic United States, we did not expect that it would be, based on how we selected panelists. However, we did realize a panel with diverse demographic characteristics, as indicated by the distribution of responses (e.g., age range, 2007 annual household income, and education level). Since our objectives were to learn whether lesser-known scab-resistant fresh apples appealed to panelists and if apples could be identified with potential to include in further research, which is a primary purpose of sensory evaluation (Schaefer, 1986), it was necessary to select consumers who represent the target market (Meilgaard et al., 2008) and not the broader public. More directly, sensory analysis of the type used in this study serves as an important first step in filtering out apples that are initial candidates for the retail fresh market. Those that are shown to be preferred by those who regularly eat apples can then be subjected to additional market research to determine one or more consumer segments that might find the specific apples to be appealing.

With "apple cultivar or type of apple" and "past purchasing of a particular apple" among the top three characteristics panelists selected as the most important when purchasing fresh apples to be eaten raw, introducing acceptable apples into an already crowded category at retail may present some challenges. Strategies for informing and persuading consumers to purchase lesser-known apples should be done in the store, which was recently cited as the primary source where consumers first learn about new products (SupermarketGuru.com, 2010). Promotions could include signage and sampling. However, these strategies received either no responses or relatively few participants, indicating that these were among the most important characteristics considered when purchasing fresh apples to be eaten raw. It is possible that their characteristics could play a supporting role, especially if "tastes like ' $\mathrm{X}$ ' apple" is used on signage, for example. Further investigation of how lesser-known scab-resistant fresh apples should be marketed is warranted to develop a promotional program for growers,

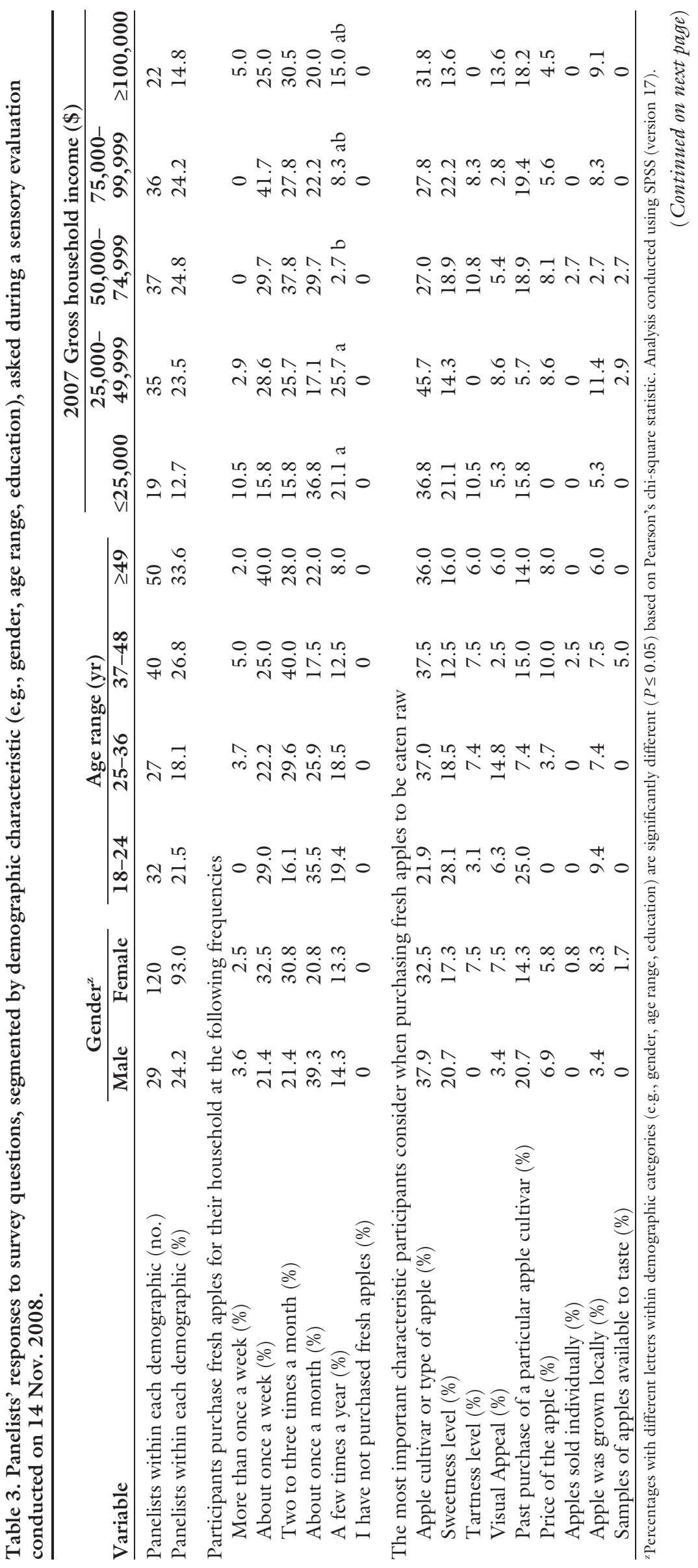




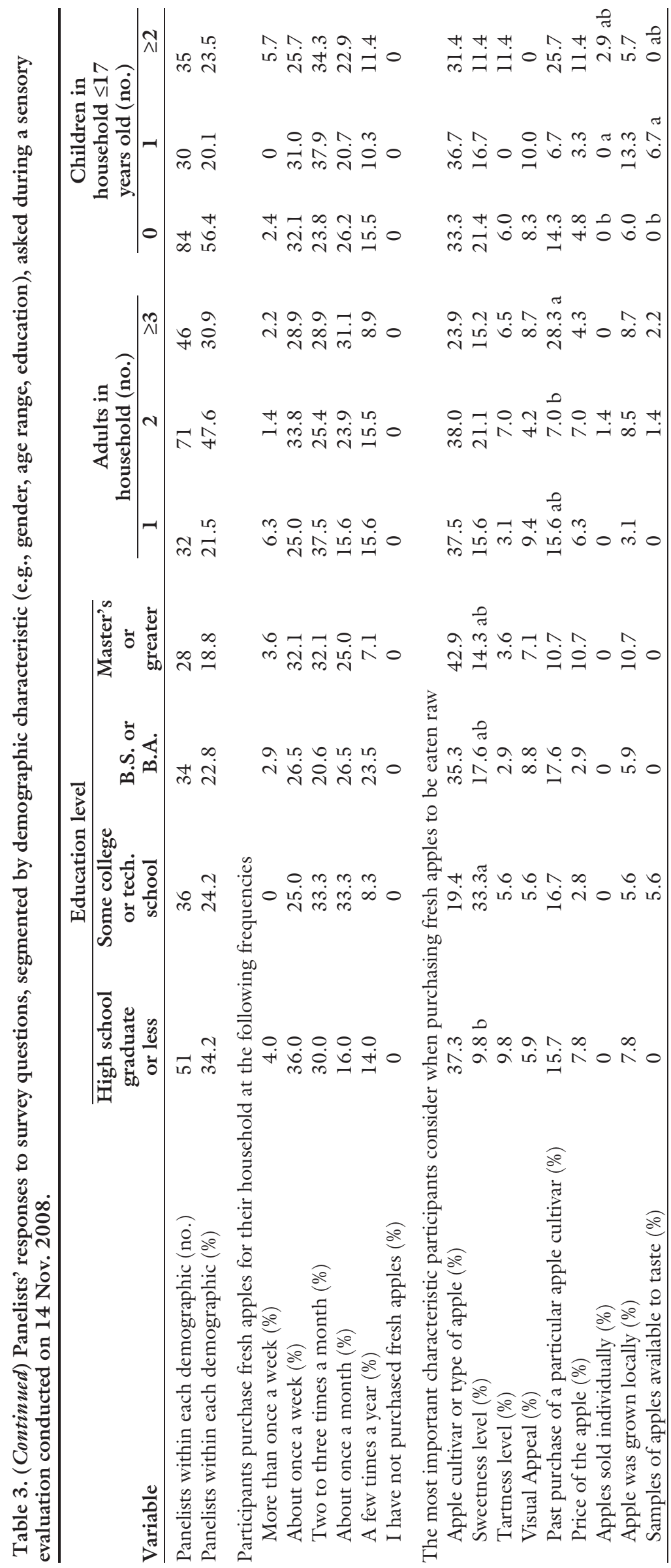

brokers, and retailers to ensure positive consumer response. It is possible, as demonstrated by apples that were once lesser-known and are now readily available (e.g., 'Fuji', 'Braeburn', and 'Gala'), to introduce additional apples that command retail shelf space.

Further understanding of consumer interest and potential demand of lesser-known apples is essential. Because of the limits on shelf space in retail outlets, which then limits the quantity and variety of products available (Drury, 2007), it is very likely that a minimal number of new apples or substitutes would be incorporated in a retailer's product mix. Taking this into consideration, additional sensory evaluations and market research should be conducted with 'Crimson Crisp' and 'Crimson Topaz' and to a lesser extent with 'GoldRush' and NY 49. In conclusion, not only should research continue to identify new apples that are strong market candidates, but educational efforts must also be implemented to reduce grower risk of altering their production plan.

\section{Literature cited}

Baker, G.A. 1999. Consumer preferences for food safety attributes in fresh apples: Market segments, consumer characteristics, and marketing opportunities. J. Agr. Resource Econ. 24:80-97.

Brown, S. and K. Maloney. 2008. Scab resistant cultivars (varieties). NY Fruit Qrtly. 16(Winter):3-6.

Cliff, M., K. Sanford, W. Wismer, and C. Hampson. 2002. Use of digital images for evaluation of factors responsible for visual preference of apples by consumers. HortScience 37:1127-1131.

Cmelik, Z., P. Zadravec, S. Tojnko, B. Schlauer, A. Vogrin, and T. Unuk. 2007. Sensory evaluation of fruit and some organically grown scab-resistant apple cultivars. Acta Hort. 737:53-58.

Crassweller, R.M. (ed.). 2008. The Pennsylvania tree fruit production guide. Pennsylvania State Univ. Publ, AGRS45. College of Agriculture Science, Penn State Cooperative Extension, Philadelphia, PA

Crosby, J., J. Janick, P. Pecknold, J. Goffreda, and S. Korban. 1994. GoldRush apple. HortScience 29:827-828.

Czernyszewicz, E. 2009. Changeability of consumer preference for some sensory features of apples. Electron. J. Pol. Agr. Univ. 12(1). 19 Feb. 2010. <http://www. 
ejpau.media.pl/volume12/issuel/art-08. html>.

Drury, C. 2007. Management and cost accounting. Cengage Learning, Florence, $\mathrm{KY}$.

Greene, D., R. Norton, C. Rom, and R. Way. 1997. Apple, p. 13-117. In: R.M. Brooks (ed.). The Brooks and Olmo register of fruit and nut varieties. 3rd ed. ASHS Press, Alexandria, VA.

Hampson, C.R., H.A. Quamme, J.W. Hall, R.A. MacDonald, M.C. King, and M.A. Cliff. 2000. Sensory evaluation as a selection tool in apple breeding. Euphytica 111:79-90.

Hough, G., I. Wakeling, A. Mucci, E. Chambers, IV, I.M. Gallardo, and L.R. Alves. 2006. Number of consumers necessary for sensory acceptability tests. Food Qual. Prefer. 17:522-526.

Janick, J., J. Goffreda, and S. Korban. 2004. 'Co-op 29' (Sundance ${ }^{\mathrm{TM}}$ ) apple. HortScience 39:450-451.

Janick, J., J. Goffreda, and S. Korban. 2006. 'Co-op 39' (CrimsonCrisp ${ }^{\mathrm{TM}}$ ) apple. HortScience 41:465-466.

Jerko, M. and K. Damir. 2008. The importance of apple attributes: A comparison of self-explicated and conjoint analysis results. Eur. Assn. Agr. Economists, 2008 Intl. Congr., 26-29 Aug. 2008, Ghent, Belgium. Abstr. 44401.
Jesionkowska, K., D. Konopacka, and W. Plocharski. 2006. The quality of apples: Preferences among consumer from Skierniewice, Poland. J. Fruit Ornamental Plant Res. 14:173-182.

Kelley, K.M. and E.S. Sánchez. 2005. Accessing and understanding consumer awareness of and potential demand for edamame [Glycine $\max ($ L.) Merrill]. HortScience 40:1347-1353.

Kuhn, B.F. and A.K. Thybo. 2001. Sensory quality of scab-resistant apple cultivars. Postharvest Biol. Technol. 23:41-50.

Manalo, A.B. 1990. Assessing the importance of apple attributes: An agricultural application of conjoint analysis. Northeast. J. Agr. Resource Econ. 19:118-124.

McCracken, V.A., B. Maier, T. Boylston, and T. Worley. 1994. Development of a scheme to evaluate consumer apple variety preferences. J. Food Distrib. Res. 25:56-63.

Meilgaard, M.C., G.V. Civille, and B.T. Carr. 2008. Sensory evaluation techniques, 4th ed. CRC Press, Boca Raton, FL.

Miller, S., C. Hampson, R. McNew, L. Berkett, S. Brown, J. Clements, R. Crassweller, E. Garcia, D. Greene, and G. Greene. 2005. Performance of apple cultivars in the 1995 NE-183 Regional Project planting. III. Fruit sensory characteristics. J. Amer. Pomol. Soc. 59:28-43.
Miller, S., R. McNew, R. Crassweller, D. Greene, C. Hampson, A. Azarenko, L. Berkett, W. Cosgill, E. Garcia, T. Lindstrom, M. Stasiak, J. Cline, B. Fallahi, E. Fallahi, and G. Greene, II. 2007. Performance of apple cultivars in the 1999 NE-183 Regional Project planting. II. Fruit quality characteristics. J. Amer. Pomol. Soc. 61:97114.

Resurreccion, A.V.A. 1998. Consumer sensory testing for product development. Aspen Publ., Gaithersburg, MD.

Richardson-Harman, N., T. Phelps, S. McDermott, and A. Gunson. 1997. Use of tactile and visual cues in consumer judgments of apple ripeness. J. Sens. Stud. 13:121-132.

Schaefer, E.E. (ed.). 1986. ASTM manual on consumer sensory evaluation. Amer. Soc. Testing Materials, Philadelphia, PA.

Stone, H. and J.L. Sidel. 2004. Sensory evaluation practices. 3rd ed. Elsevier Academic Press, San Diego, CA.

SupermarketGuru.com. 2010. Consumer first aware of new products at the shelf. 10 May 2010. <http://www.supermarket guru.com/index.cfm/go/sg.viewArticle/ articleId/1233>.

The NPD Group. 2009. NPD reports "better for you" foods to grown significantly over the next decade. 6 Aug. 2009. <www.npd.com/press/releases/pres_ 090707a.html>. 